\title{
International findings with the Achenbach System of Empirically Based Assessment (ASEBA): applications to clinical services, research, and training
}

\author{
Thomas M. Achenbach ${ }^{*}$ (D)
}

\begin{abstract}
The purpose of this invited article is to present multicultural norms and related international findings obtained with the Achenbach System of Empirically Based Assessment (ASEBA) by indigenous researchers in over 50 societies. The article describes ASEBA instruments for which multicultural norms are available, plus procedures for constructing the multicultural norms. It presents applications to clinical services, including use of multi-informant data for assessing children and their parents. The Multicultural Family Assessment Module (MFAM) enables mental health providers to view side-by-side bar graphs of child and parent scores on syndromes, DSM-oriented scales, Internalizing, Externalizing, and Total Problems. Evidence-based assessment of progress and outcomes is facilitated by the Progress \& Outcomes App (P\&O App). Research applications are outlined, including longitudinal and outcomes research. Applications to training mental health providers include having trainees study standardized multi-informant assessment data prior to interviewing children and their parents. Trainees can also sharpen their clinical skills by completing assessment forms to describe children and their parents, and then using ASEBA software to compare their ratings with ratings by children, parents, and other informants. Practical evidence-based assessment instruments with multicultural norms enable mental health providers, researchers, and trainees to perform intake, progress, and outcome assessments of children and their parents in terms of a standardized international clinical data language.
\end{abstract}

Keywords: Multicultural, ASEBA, Norms, Multi-informant, International, Mental health services

\section{Background}

This article was invited by CAPMH Editor Joerg Fegert. Its purpose is to present multicultural norms and related international findings obtained with the Achenbach System of Empirically Based Assessment (ASEBA) by indigenous researchers in over 50 societies from every inhabited continent. The article describes ASEBA instruments for which multicultural norms are available and procedures for constructing the multicultural norms. It presents applications to clinical services, including use of multi-informant data for assessing children and their

*Correspondence: childpsy@together.net

Department of Psychiatry, University of Vermont, 1 South Prospect Street, Burlington, VT 05401, USA parents. The Multicultural Family Assessment Module (MFAM) enables mental health providers to view side-by-side bar graphs of parent and child scores on syndromes, DSM-oriented scales, Internalizing, Externalizing, and Total Problems. Evidence-based assessment of progress and outcomes is facilitated by the Progress \& Outcomes App (P\&O App). Research applications are outlined, including longitudinal and outcomes research. Applications to training mental health providers include having trainees study standardized multi-informant assessment data prior to interviewing parents and children. Trainees can also sharpen their clinical skills by completing assessment forms to describe parents and children and then using ASEBA software to compare

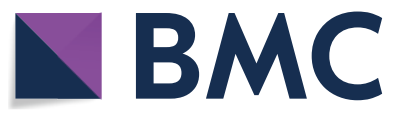

(c) The Author(s) 2019. This article is distributed under the terms of the Creative Commons Attribution 4.0 International License (http://creativecommons.org/licenses/by/4.0/), which permits unrestricted use, distribution, and reproduction in any medium, provided you give appropriate credit to the original author(s) and the source, provide a link to the Creative Commons license, and indicate if changes were made. The Creative Commons Public Domain Dedication waiver (http://creativecommons.org/ publicdomain/zero/1.0/) applies to the data made available in this article, unless otherwise stated. 
their completed forms with forms completed by parents and youths.

\section{Main text}

The ASEBA includes standardized assessment instruments for obtaining self- and collateral-reports of behavioral, emotional, social, and thought problems and strengths manifested by people from age $1 \frac{1 / 2}{2}$ to $90+$ years. The ASEBA also includes instruments for assessing children's functioning during clinical interviews and during individual ability and achievement tests [1], which are not addressed in this article. The self- and collateralreport instruments are tailored to assessment of people

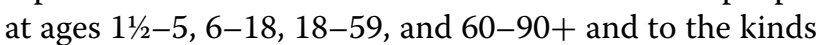
of informants who are appropriate for the assessed person's age.

The purpose of this article is to present multicultural norms and related international findings obtained by collaborating indigenous researchers in over 50 societies from every inhabited continent. ("Societies" refer to geopolitically demarcated populations having a dominant language, including countries but also distinctive populations that do not comprise countries, such as Hong Kong, Puerto Rico, and Flanders-the Flemish-speaking region of Belgium.) The main focus will be on ages $1 \frac{12}{2}-18$, for which "children" will be used. However, because parents and other adults must be involved in efforts to help children, multicultural aspects of adult assessment will also be addressed. After international findings are presented, applications to clinical services, research, and training will be outlined.

\section{ASEBA instruments having multicultural norms}

The ASEBA instruments for which multicultural norms have been constructed are standardized forms that include items that describe a broad spectrum of problems. Informants rate the problem items as $0=$ not true (as far as you know), 1=somewhat or sometimes true, or
$2=$ very true or often true over periods specified on the forms, such as 2 months or 6 months.

The problem items are worded to be easily understood by the kinds of informants for whom they are intended. As an example, the Child Behavior Checklist for Ages 6-18 (CBCL/6-18) is designed to be completed by parent figures who are asked to provide 0-1-2 ratings of items such as Acts too young for age; Can't concentrate, can't pay attention for long; Cruel to animals; Gets in many fights; Unhappy, sad, or depressed; and Worries. The items have been selected and refined through many iterations of testing with clinical and population samples to assess problems that are found to be significantly associated with clinical status and that are well-understood by the intended informants. Most of the forms also include items for assessing various kinds of strengths. The forms can be self-administered online or on paper or can be administered by interviewers without specialized training. Table 1 lists the ASEBA forms addressed in this article, while Table 2 lists languages in which translations of the forms are available.

Testing empirically derived syndromes in multiple societies The problem items of the forms listed in Table 1 have been factor analyzed to identify syndromes of problems that tend to co-vary in ratings by each kind of informant for a particular age range. This constitutes a "bottom-up" approach to constructing taxonomies of psychopathology based on ratings of large samples of individuals on each form. The initial factor analyses were done on ratings for Anglophone populations, mainly in the US. However, to test the generalizability of the syndromes to other societies, the syndromes derived from Anglophone samples were used as models in confirmatory factor analyses (CFAs) of ratings of population samples from dozens of other societies [11-19, 24].

The CFA findings have supported the syndromes derived from Anglophone samples in all societies

Table 1 Self- and collateral-assessment instruments having multicultural norms

\begin{tabular}{|c|c|c|}
\hline Age ranges & Instruments & Informants \\
\hline \multirow[t]{2}{*}{$1 \frac{1}{2}-5$} & Child Behavior Checklist for Ages 11/2-5 (CBCL/11/2-5) & Parent figures \\
\hline & Caregiver-Teacher Report Form (C-TRF) & Daycare providers; preschool teachers \\
\hline \multirow[t]{2}{*}{$6-18$} & Child Behavior Checklist for Ages 6-18 (CBCL/6-18) & Parent figures \\
\hline & Teacher's Report Form (TRF) & Teachers; school counselors \\
\hline $11-18$ & Youth Self-Report (YSR) & Youths \\
\hline \multirow[t]{2}{*}{$18-59$} & Adult Self-Report (ASR) & Adults \\
\hline & Adult Behavior Checklist (ABCL) & Adult collaterals \\
\hline \multirow[t]{2}{*}{$60-90+$} & Older Adult Self-Report (OASR) & Older adults \\
\hline & Older Adult Behavior Checklist (OABCL) & Older adult collaterals \\
\hline
\end{tabular}


Table 2 Translations of ASEBA forms

\begin{tabular}{|c|c|c|}
\hline 1. Afaan Oromo (Ethiopia) & 36. Georgian & 71. Polish \\
\hline 2. Afrikaans & 37. German & 72. Portuguese (Angola, Portugal) \\
\hline 3. Albanian/Kosova & 38. Greek & 73. Portuguese (Brazilian) \\
\hline 4. American Sign Language & 39. Gujarati (India) & 74. Portuguese Creole \\
\hline 5. Amharic (Ethiopia) & 40. Haitian Creole & 75. Punjabi (India) \\
\hline 6. Arabic & 41. Hebrew & 76. Romanian \\
\hline 7. Armenian & 42. Hindi (India) & 77. Russian \\
\hline 8. Auslan (Australian Sign Language) & 43. Hungarian & 78. Sami (Norway) \\
\hline 9. Bahasa (Indonesia) & 44. Icelandic & 79. Samoan \\
\hline 10. Bahasa (Malaysia) & 45. Italian & 80. Sepedi (Northern Sotho) \\
\hline 11. Bangla (Bangladesh) & 46. Japanese & 81. Serbian \\
\hline 12. Basque (Spain) & 47. Kannada (India) & 82. Sesotho (Southern Sotho) \\
\hline 13. Bemba (Zambia) & 48. Khmer (Cambodia) & 83. Sinhala (Sri Lanka) \\
\hline 14. Bengali (India) & 49. Kiembu (Kenya) & 84. Slovak \\
\hline 15. Bosnian & 50. Kikamba (Kenya) & 85. Slovene \\
\hline 16. Braille & 51. Kiswahili (Kenya) & 86. Somali \\
\hline 17. British Sign Language & 52. Korean & 87. Spanish (Castilian) \\
\hline 18. Bulgarian & 53. Laotian & 88. Spanish (Latino) \\
\hline 19. Burmese (Myanmar) & 54. Latvian & 89. Swahili \\
\hline 20. Catalan (Spain) & 55. Lithuanian & 90. Swedish \\
\hline 21. Cebuano (Philippines) & 56. Luganda (Uganda) & 91. Tagalog (Philippines) \\
\hline 22. Chinese & 57. Luo (Uganda) & 92. Tamil (India) \\
\hline 23. Croatian & 58. Macedonian & 93. Telugu (India) \\
\hline 24. Czech & 59. Malayalam (India) & 94. Thai \\
\hline 25. Danish & 60. Maltese & 95. Tigrinya (Eritrea) \\
\hline 26. Dutch (Netherlands, Flanders) & 61. Manipuri (India) & 96. Tibetan \\
\hline 27. Estonian & 62. Marathi (India) & 97. TshiVenda (South Africa) \\
\hline 28. Farsi/Persian (Iran) & 63. Mauritian Creole & 98. Turkish \\
\hline 29. Finnish & 64. Montenegrin & 99. Ukrainian \\
\hline 30. Flemish & 65. Nepalese & 100. Urdu (India, Pakistan) \\
\hline 31. French (Belgian) & 66. Norwegian & 101. Vietnamese \\
\hline 32. French (Canadian) & 67. Nyanja (Zambia) & 102. Visayan (Philippines) \\
\hline 33. French (Parisian) & 68. Omoro (Ethiopia) & 103. Xhosa (South Africa) \\
\hline 34. Ga (Ghana) & 69. Papiamento (Curacao) & 104. Zulu \\
\hline 35. Galician (Spain) & 70. Pashto (Afghanistan, Pakistan) & \\
\hline
\end{tabular}

Languages into which at least one ASEBA form has been translated. Please visit http://www.aseba.org for updated lists of translations of each ASEBA form

analyzed to date. Although it is possible that problem items not included on the ASEBA forms and/or other analytic methods might reveal additional syndromes in some societies, the following six syndromes derived from parent and caregiver/teacher ratings for ages $1 \frac{1}{2}-5$ have been supported in dozens of societies: Emotionally Reactive, Anxious/Depressed, Somatic Complaints, Withdrawn, Attention Problems, and Aggressive Behavior. An additional syndrome-designated as Sleep Problems-has also been supported for parent ratings. For ages 6-18, the following eight syndromes derived from parent-, teacher-, and youth self-ratings have been supported in dozens of societies: Anxious/Depressed, Withdrawn/Depressed,
Somatic Complaints, Social Problems, Thought Problems, Attention Problems, Rule-Breaking Behavior, and Aggressive Behavior.

\section{Constructing multicultural norms}

Even though the patterns of co-varying problems embodied in the empirically derived syndromes were supported in dozens of societies, this does not necessarily mean that scores on the syndrome scales (sum of 0-1-2 ratings on the items comprising a scale) are similar in all societies. If the scores tend to be higher in some societies than in others, such differences need to be taken into account when assessing children in the different societies. To compare 
the magnitudes of problem scores across different societies, the mean Total Problems scores (sum of 0-1-2 ratings on all problem items on a form) were computed for population samples from each society. For a particular form-such as the CBCL/6-18, the mean Total Problems scores from all available societies were averaged to obtain the "omnicultural mean", i.e., the mean of the mean Total Problems scores for all the available societies. Figure 1 displays bar graphs that span from the 5th to the 95th percentile CBCL/6-18 Total Problems scores in each of 31 societies.

The star in the middle of each bar indicates the mean Total Problems score for that society. Even though there were statistically significant differences between the scores for the different societies, the 5th to 95th percentile distributions for every society overlap with those for every other society. Thus, many children in Japan-the society with the lowest mean Total Problems scoreobtained scores that overlap with scores obtained by children in Puerto Rico-the society with the highest mean Total Problems score. In other words, no society differed categorically from any other society in having scores that were all lower or all higher than in another society.

For each ASEBA form listed in Table 1, societies were identified whose mean Total Problems scores were more than one standard deviation $(S D)$ below the omnicultural mean. These societies with relatively low problem scores on a particular form were designated as Multicultural Group 1. Scale scores from all the Group 1 societies were then combined to compute norms for each of the empirically derived syndromes. Norms were also computed for the Total Problems (general psychopathology) scale and for other scales scored from the ASEBA problem items. Other scales included DSM-oriented scales comprising problems identified by international experts as being very consistent with DSM-5 diagnoses [5], plus broad spectrum Internalizing and Externalizing scales [4].

In addition to the sets of multicultural norms for Group 1 societies, sets of multicultural norms were also constructed for societies whose mean Total Problems scores were $>1 S D$ above the omnicultural mean. These societies with relatively high problem scores were designated as Multicultural Norm Group 3. For some forms, the mean Total Problems score for the US normative sample was at the middle of the scores for the societies with mean Total Problems scores ranging from $1 S D$ below to $1 S D$ above the omnicultural mean. For those forms, the widely used US norms are used for Multicultural Norm Group 2 societies. For other forms, Group 2 norms were constructed according to the

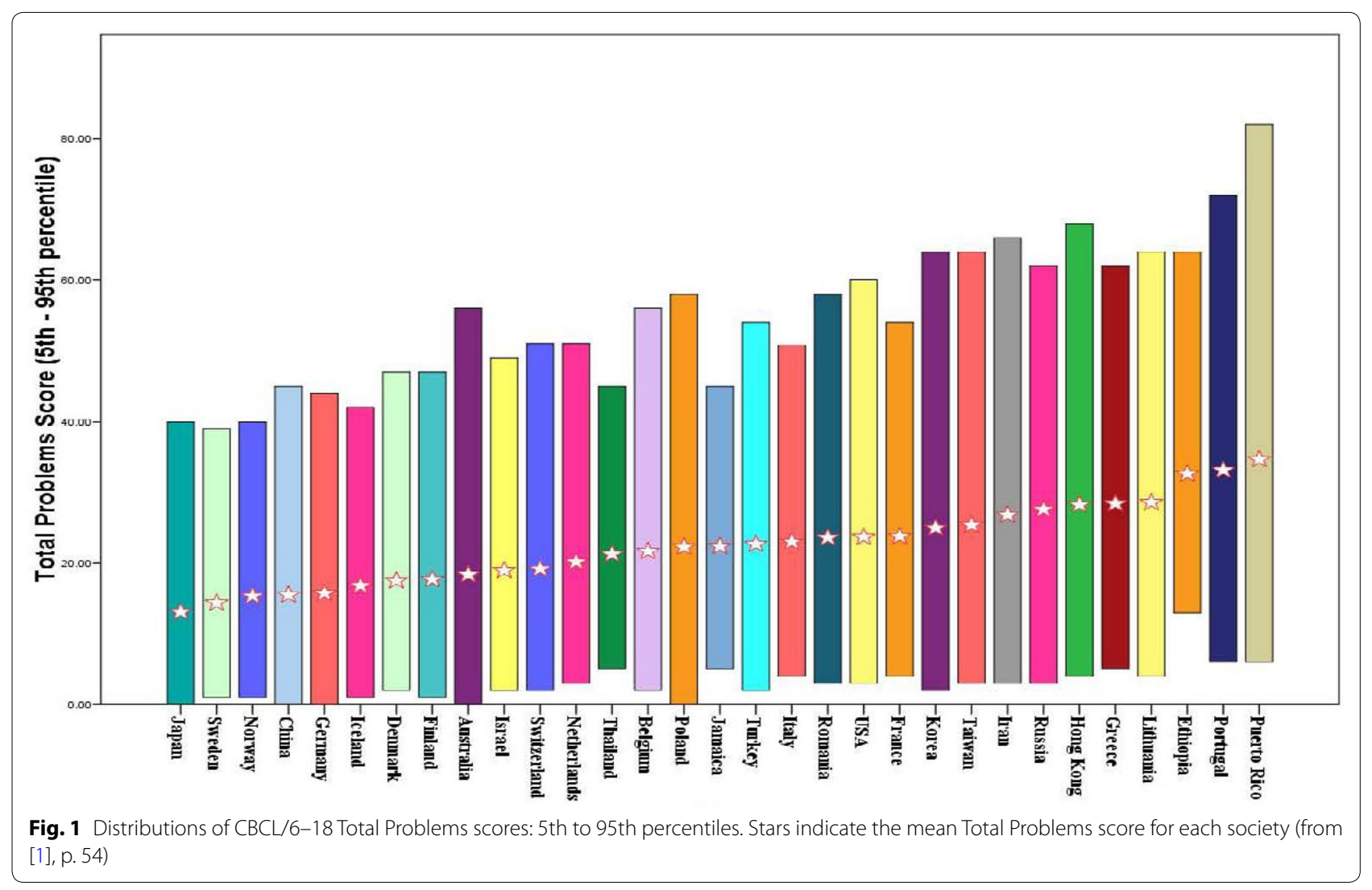


procedures described for Group 1 and Group 3. Computer software for scoring ASEBA forms enables users to display scale scores in relation to Group 1, Group 2, or Group 3 norms, depending on the societies that are relevant to the person being assessed and the informants completing collateral-report forms. Figure 2 summarizes the procedures for constructing and applying multicultural norms.

The distributions of problem scores shown in Fig. 1 resemble the broad population distributions typically found for characteristics such as height and weight. The fact that societies differ with respect to their average problem scores, their average height, and their average weight means that those societal differences need to be reflected in norms for particular societies. Nevertheless, within each society, individual differences in problem scores, height, and weight must be identified to characterize each individual in the society. The ASEBA Multicultural Norm Groups enable users to separate societal effects from their assessment of individual children within societies.

In addition to societal effects, there may also be cultural effects that are not perfectly correlated with societal effects. However, hierarchical linear modeling analyses have shown that societal effects exceeded cultural effects and that the sum of societal effects plus cultural effects accounted for only about $10 \%$ of the variation in CBCL/6-18 scores obtained by 72,493 children living in 45 societies nested within 10 culture clusters (e.g., Anglo, Confucian) from every inhabited continent [23]. The finding that about $10 \%$ of the variation in problem scores is accounted for by societal and cultural effects means that most of the variation in problem scores is accounted for by effects associated with individual differences among children. In other words, most of the variation in $\mathrm{CBCL} / 6-18$ problem

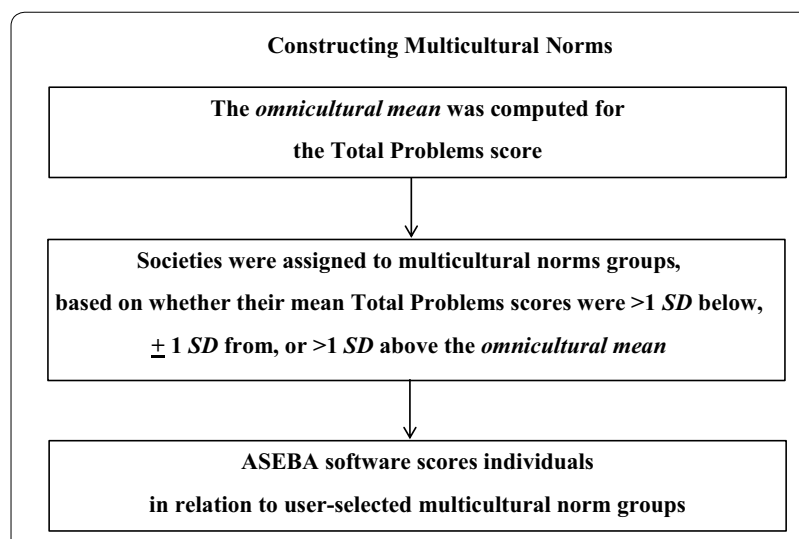

Fig. 2 Procedures for constructing and applying multicultural norms (from [3]) scores reflects differences among problems reported by parents for individual children within their societies and culture clusters.

\section{Applications to clinical services}

Efforts to obtain help for children's behavioral, emotional, social, and thought problems typically require information from adults, such as parents, caregivers, and teachers. The $\mathrm{CBCL} / 1 \frac{1 / 2-5}{2}$ and $\mathrm{CBCL} / 6-18$ enable parents and others who see children in their home environments to provide ratings and personal comments on a broad spectrum of problems. Both forms also ask informants to describe what concerns them most about the child and the best things about the child. The CBCL/11/2-5 includes the Language Development Survey, which can identify delayed speech. The CBCL/6-18 includes items for assessing competencies in terms of the child's functioning in activities, social relationships, and school. The Caregiver-Teacher Report Form (C-TRF) enables preschool teachers and daycare providers to provide ratings and comments on many of the same problems assessed

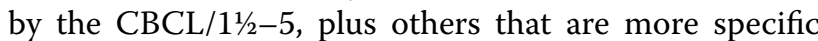
to group settings. The Teacher's Report Form (TRF) enables teachers and school counselors to provide ratings and comments on most of the same problems as the $\mathrm{CBCL} / 6-18$, plus problems and adaptive functioning specific to school contexts. The Youth Self-Report (YSR) enables 11-18-year-olds to rate many of the same problems and competencies as are rated on the CBCL/6-18, plus the youth's own positive qualities.

\section{Use of data from multiple informants}

Most providers of child mental health services recognize that information is needed from multiple informants who can report on different aspects of a child's functioning in different contexts. Differences between parent and teacher reports, for example, may reflect both differences in how a child functions at home versus school and differences in how the child is perceived by parents versus teachers. To help providers take account of the discrepancies that often occur between informants' reports [8], ASEBA software displays bar graph comparisons between scores obtained from up to 10 informants for syndromes, DSM-oriented scales, Internalizing, Externalizing, and Total Problems. Scale scores are standardized on the basis of norms for the child's age, gender, the type of informant (parent, teacher, self), and the relevant multicultural norm group.

\section{Multicultural family assessment module (MFAM)}

When parent figures are available, it is often as important to assess them as to assess the child who needs help. This can be done by asking each parent figure to complete the 
Adult Self-Report (ASR) to rate and report on their own problems and strengths. If more than one parent figure is available, each can also be asked to complete the Adult Behavior Checklist (ABCL) to describe their partner. The Multicultural Family Assessment Module (MFAM) is an app that can display bar graphs of ASR and ABCL scale scores alongside CBCL/6-18, TRF, and YSR scale scores. As seven ASR and ABCL syndromes have counterparts scored from the CBCL/6-18, TRF, and YSR, mental health providers can directly compare parent and child scores on the counterpart syndromes. In some cases, such comparisons may reveal similarities between parent and child problems, as has been found in US and Dutch studies [27, 29].

As an example, Fig. 3 displays MFAM bar graphs for syndrome scales scored from ASRs completed by Martin and Lana to describe themselves, bar graphs scored from ABCLs completed by Martin and Lana to describe each other, and bar graphs scored from CBCL/6-18 forms completed by Martin and Lana to describe their 11-yearold son Robert, plus TRF and YSR forms completed to describe Robert (names and personal details are fictitious). By looking at the middle bar graphs in the middle row of Fig. 3, the provider can see that the Thought Problems syndrome scale scores are elevated for the ASR and $\mathrm{ABCL}$ that describe Lana, as well as for the CBCL/6-18, TRF, and YSR forms that describe her son Robert. The Thought Problems syndrome scale scored from the ABCL completed by Lana to describe her partner Martin also reached the bottom of the borderline clinical range (the bottom broken line in Fig. 3). These results provide evidence that Lana and her son Robert, and to a lesser degree Robert's father Martin may be experiencing thought problems.

Other bar graphs in Fig. 3 indicate that Robert has elevated levels of problems of the Anxious/Depressed and Withdrawn/Depressed syndromes according to parent, teacher, and self-ratings, plus an elevated level on the Attention Problems syndrome scored from the TRF and a less elevated level on the Attention Problems syndrome scored from the YSR. On the Social Problems syndrome (not scored from the ASR or $\mathrm{ABCL}$ ), Robert's CBCL/6-18, TRF, and YSR forms all yielded scores in the clinical range (above the top broken line). On the Intrusive syndrome (scored only from the ASR and $\mathrm{ABCL}$ ) and on the Aggressive Behavior

\begin{tabular}{|c|c|c|c|c|c|c|c|c|c|c|c|c|c|c|c|}
\hline \multicolumn{16}{|c|}{ Multi-Informant Comparison - Syndrome Scale T Scores } \\
\hline Form & Eval ID & Assessed Person & Age & Informant & Relation & Society & Date & Form & Eval ID & Assessed Person & Age & Informant & Relation & Society & Date \\
\hline $\mathrm{ABC1}$ & 01 & Cross, Lana & 39 & Cross, Martin & Spouse & Group 1 & $02 / 01 / 2014$ & СBC6 & 02 & Cross, Robert & 11 & Cross, Lana & Parent & Group 1 & $02 / 01 / 2014$ \\
\hline ASR2 & 02 & Cross, Lana & 39 & & Self & Group 1 & $02 / 01 / 2014$ & TRF7 & 03 & Cross, Robert & 11 & Hotchkiss, Mary & Teacher & Group 1 & $01 / 01 / 2014$ \\
\hline $\mathrm{ABC} 3$ & 01 & Cross, Martin & 40 & Cross, Lana & Spouse & Group 1 & $02 / 02 / 2014$ & YSR8 & 04 & Cross, Robert & 11 & & Self & Group 1 & $02 / 02 / 2014$ \\
\hline ASR 4 & 02 & Cross, Martin & 40 & & Self & Group 1 & $01 / 31 / 2014$ & & & & & & & & \\
\hline CBC5 & 01 & Cross, Robert & 11 & Cross, Martin & Parent & Group 1 & $01 / 03 / 2014$ & & & & & & & & \\
\hline
\end{tabular}
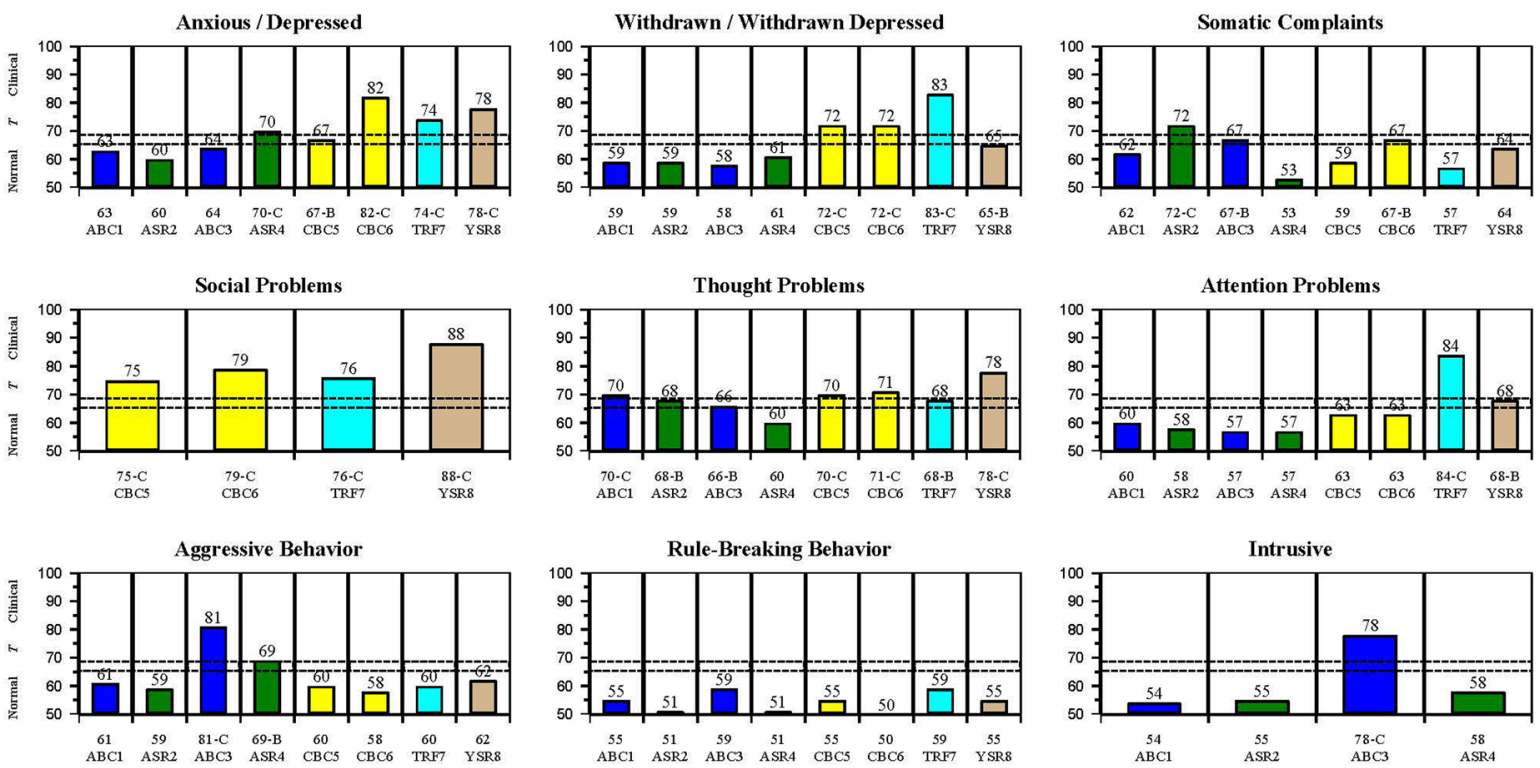

$B=$ Borderline clinical range $C=$ Clinical range; Broken Lines $=$ Borderline clinical range

Fig. 3 MFAM bar graphs of syndrome scores for Martin, Lana, and their son Robert (from [3]) 
syndrome, Lana's ABCL ratings of her partner Martin yielded scores well up in the clinical range.

The mental health provider working with Robert, Martin, and Lana can elect to show the MFAM bar graphs to Martin and Lana to help them appreciate similarities and differences between how they see themselves and are seen by their partner. This may help them understand how perceptions of their son Robert may also differ and how problems reported for Robert may relate to their own functioning.

\section{Assessing progress and outcomes}

Evidence-based practice entails obtaining explicit evidence about children's functioning and needs when the children are initially assessed in order to design appropriate interventions. However, evidence-based practice should also include assessments to evaluate progress and outcomes. Assessments of progress should compare children's functioning after interventions are implemented with their functioning at intake in order to determine whether functioning is improving. If not, changes in the interventions may be warranted. Assessments of outcomes should compare children's functioning when interventions are ending with their functioning at intake in order to determine whether functioning has improved sufficiently to warrant ending services. If standardized assessment instruments are used to obtain data from multiple informants at intake, some or all of the same informants can be asked to complete the assessment instruments again in order to assess progress and outcomes.

To facilitate the assessment of progress and outcomes and to determine whether changes exceed chance expectations, the Progress \& Outcomes App (P\&O App; [2]) enables providers to compare ASEBA scale scores obtained at intake into a service with scores obtained at subsequent provider-selected intervals for progress and outcome assessments. The $\mathrm{P} \& \mathrm{O}$ App displays bar graphs of scale scores for each assessment, plus text statements regarding whether changes in scores exceed chance expectations, as determined by statistical criteria applied by the P\&O App. Providers do not need any statistical skills to have the $P \& O$ App determine whether changes in scale scores for individual children exceed chance expectations. However, for providers, agencies, and researchers wishing to compare the effectiveness of different interventions with each other and/or with control conditions, the P\&O App can also provide statistical analyses for comparing the progress and outcomes of groups receiving different conditions.

\section{Applications to research}

ASEBA forms are widely used in research, with over 10,000 publications reporting their use in over a hundred societies and cultural groups [7]. Research applications of ASEBA forms include epidemiological studies of the prevalence and patterning of problems in many societies, as exemplified by the Rescorla et al. [23, 24] studies of problems reported for population samples of children in dozens of societies.

ASEBA forms are especially well suited to research that requires re-assessments of children over long periods, such as studies of the outcomes and effectiveness of particular interventions and longitudinal studies of the developmental course, correlates, and outcomes of diverse problems and strengths. Because ASEBA forms include developmentally appropriate items, scales, con-

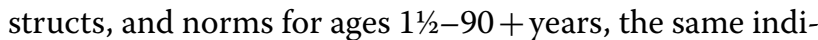
viduals can be repeatedly assessed with ASEBA forms as they advance through successive developmental periods. Moreover, the standardization of ASEBA data across developmental periods facilitates statistical analyses for identifying continuities and changes in individuals' functioning as they develop.

Examples of longitudinal studies employing ASEBA assessments that have yielded many findings on the developmental course, correlates, and outcomes of diverse problems and strengths include the US National Longitudinal Study of a representative sample of over 2000 US children assessed over 9 years into early adulthood [28]; the Zuid Holland Longitudinal Study of over 2000 Dutch children assessed over 24 years into middle adulthood, when the original participants' children were also assessed [22, 26]; the TRacking Adolescents Individual Lives Survey (TRAILS) of Dutch adolescents, including a population sample of over 2000 youths and a clinical sample of over 500 youths [20]; the Generation R Study ("R" = Rotterdam) that started with 8880 pregnant women [25]; and the Netherlands Twin Registry that has assessed twins born in the Netherlands each year since 1987 and has re-assessed them as they developed into adulthood [10].

Among the many studies generated by the Netherlands Twin Registery is one that estimated genetic and environmental variance in scores on the $\mathrm{CBCL} / 1 \frac{112-5}{2}$ Pervasive Developmental Problems scale ("Autistic Spectrum Problems" scale since DSM-5 was published) [9]. Based on data for 38,798 3-year-old twins, genetic effects accounted for $78 \%$ of the variance in boys' scores and $83 \%$ of the variance in girls' scores. Nevertheless, $29 \%$ of monozygotic twins were discordant for clinical versus normal range scores, suggesting that environmental factors might provide resilience for some children, despite high genetic risk. 
ASEBA forms are widely used to test the effects of interventions in randomized clinical trials (RCTs), where children receiving different intervention and control conditions are assessed with ASEBA forms at intake and again following the intervention conditions. As an example, computerized cognitive training was provided to randomly selected Ugandan children who had survived cerebral malaria, while a randomly selected control group did not receive training [6]. Before and after the training periods, parents or surrogates completed the CBCL/618 and the children received six cognitive tests. The intervention group improved significantly more than the control group on the CBCL/6-18 Internalizing scale and on 3 of the 6 cognitive tests and nonsignificantly more on the CBCL/6-18 Externalizing and Total Problems scales, as well as on the other three cognitive tests. The authors concluded that the training could improve the behavioral and cognitive functioning of children who had survived cerebral malaria.

As another example, an RCT of an omega-3 dietary supplement for children in Mauritius was followed by significantly lower CBCL Internalizing and Externalizing scores for children receiving omega- 3 than for children receiving a placebo [21].

\section{Applications to training}

Mental health trainees can learn the value of obtaining and comparing evidence from parent-, teacher-, and self-reports by working with children for whom the CBCL, C-TRF, TRF, and/or YSR are completed. Trainees can study a completed CBCL before interviewing a parent or a completed YSR before interviewing a youth and can then ask the interviewee if they have any questions about the form. This often elicits responses that provide leads regarding the respondent's concerns. Trainees can also ask about items that were endorsed on the form. For example, if a parent gave a 1 or 2 rating to Can't get mind off certain thoughts and wrote "death" in the space that invites a description of the problem, the trainee can mention the parent's response and ask the parent to talk about it. If a youth gives a 1 or 2 rating to the YSR item $I$ feel that others are out to get me, the trainee can ask the youth to talk about it. Parents and youths often report many more problems on the CBCL and YSR than they would spontaneously volunteer in interviews.

By viewing comparisons of CBCL, C-TRF, TRF, and/or YSR item and scale scores that are displayed by ASEBA software, trainees can identify specific consistencies and discrepancies between reports by different informants. Trainees can thus identify problems likely to warrant a broad-gauged intervention because they are reported by all informants versus problems that may warrant a more situation-specific approach because they are reported to occur in only one context, such as home or school. Other problems may be specific to interactions with only one informant, such as one parent or one teacher.

If parents are asked to complete the ASR to describe themselves and to complete the ABCL to describe their partner, the MFAM can be used to display bar graphs of scores obtained from the ASR and ABCL alongside bar graphs of scores obtained from the CBCL/6-18, TRF, and/or YSR. By comparing the parent and child scores, trainees can identify similarities and differences between their scores as an aid to formulating intervention plans and deciding whether to show the MFAM output to parents. After trainees are acquainted with the parents and child, they can also fill out ABCL and CBCL forms for comparison with the forms completed by family members. To sharpen their clinical skills, trainees can then discuss discrepancies between the trainee-completed forms versus the parent-completed forms with the trainees' supervisors. After interventions have been implemented, parents and/or youths can be asked to complete the forms again to evaluate progress and outcomes. If trainees (blind to the forms completed by family members) then complete the relevant forms, they can have ASEBA software compare them with the results obtained from family members to sharpen their skills for evaluating progress and outcomes.

\section{Summary and conclusions}

This article presented multicultural norms and related international findings obtained via standardized forms for ages $1 \frac{1 / 2}{2}-90+$ years by collaborating indigenous researchers in over 50 societies from every inhabited continent. Based on assessment of population samples, the multicultural norms enable mental health providers to display individuals' scores for syndromes, DSM-oriented scales, Internalizing, Externalizing, and Total Problems in relation to norms for the assessed person's age, gender, the type of informant who provided assessment data, and the appropriate multicultural norm group.

Because children's functioning often differs from one context to another-such as home versus school-and because perceptions of children also differ, it is essential to obtain data from multiple informants, such as a child's mother, father, teacher(s), and the child. Parallel assessment forms designed for completion by parents, teachers, and youths are scored via software that displays side-by-side comparisons of item and scale scores. Providers can thus identify consistencies and discrepancies between reports by different informants to consider in planning interventions.

Because parent figures play key roles in efforts to help children, self- and collateral-report forms for parents can be used to document and compare parents' functioning 
with their children's functioning. Evidence-based practice entails obtaining explicit evidence regarding functioning at intake into services and again on subsequent occasions to assess progress and outcomes, which can be done with the Progress \& Outcomes App.

Applications to clinical services, research, and training were presented to demonstrate the value of using the same standardized assessment instruments for many purposes in diverse populations around the world.

\section{Limitations and future directions}

The ASEBA provides practical instruments for the phenotypic assessment of psychopathology and strengths, based on self- and collateral-reports, scored from a finite set of items. Although respondents are encouraged to describe additional problems and strengths, different items and analyses may well produce different results. Developmental histories, interviews, observations, and biomedical procedures also contribute to comprehensive assessment. Moreover, genetic, behavioral, neurobiological, and other research methods are essential for advancing knowledge of influences on the phenotypic psychopathology and strengths assessed by the ASEBA.

For the future, multicultural collaborations on evidence-based assessment will continue to expand beyond the $50+$ societies from which indigenous collaborators have contributed data. A key objective is to disseminate evidence-based assessment tools, attitudes, and practices in order to ensure that initial evaluations provide data with which to optimize interventions and against which to measure changes at subsequent progress and outcome assessments.

\footnotetext{
Abbreviations

CBCL/1 1/2-5 and CBCL/6-18: Child Behavior Checklist; CFA: confirmatory factor analysis; DSM: diagnostic and statistical manual; TRF: Teacher's Report Form; YSR: Youth Self-Report; MFAM: Multicultural Family Assessment Module; ASR: Adult Self-Report; ABCL: Adult Behavior Checklist; P\&O App: Progress \& Outcomes App; RCT: randomized clinical trial; C-TRF: Caregiver-Teacher Report Form.
}

\section{Acknowledgements}

None.

\section{Authors' contributions}

TMA wrote article. The author read and approved the final manuscript.

\section{Funding}

The nonprofit University of Vermont Research Center for Children, Youth, and Families funds salaries for TMA and clerical support personnel

\section{Availability of data and materials}

No datasets were generated or analyzed for this article

Ethics approval and consent to participate

Not applicable.

Consent for publication

Not applicable.

\section{Competing interests}

Created by TMA and colleagues, the ASEBA is published by the nonprofit University of Vermont Research Center for Children, Youth, and Families, from which TMA receives remuneration.

Received: 21 March 2019 Accepted: 24 June 2019

Published online: 05 July 2019

\section{References}

1. Achenbach TM. The Achenbach System of Empirically Based Assessment (ASEBA): Development, findings, theory, and applications. Burlington: University of Vermont Research Center for Children, Youth, and Families; 2009.

2. Achenbach TM. ASEBA manual for assessing progress and outcomes of problems and strengths. University of Vermont Research Center for Children, Youth, \& Families, Burlington, VT. 2020.

3. Achenbach TM, Rescorla LA. Multicultural supplement to the manual for the ASEBA adult forms \& profiles. Burlington: University of Vermont Research Center for Children, Youth, and Families; 2015.

4. Achenbach TM, Ivanova MY, Rescorla LA, Turner LV, Althoff RR. Internalizing/externalizing problems: review and recommendations for clinical and research applications. J Am Acad Child Adolesc Psychiatry. 2016;55:647-56.

5. American Psychiatric Association. Diagnostic and statistical manual of mental disorders. 5th ed. Washington, DC: Author; 2013.

6. Bangirana P, Giordani B, John CC, Page C, Opoka RO, Boivin MJ. Immediate neuropsychological and behavioral benefits of computerized cognitive rehabilitation in Ugandan pediatric cerebral malaria survivors. J Dev Behav Pediatr. 2009:30:310-8.

7. Bérubé RL, Achenbach TM. Bibliography of published studies using the Achenbach System of Empirically Based Assessment (ASEBA). Burlington: University of Vermont Research Center for Children, Youth, and Families; 2019.

8. De Los Reyes A, Augenstein TM, Wang M, Thomas SA, Drabick DAG, Burgess DE, Rabinowitz J. The validity of the multi-informant approach to assessing child and adolescent mental health. Psychol Bull. 2015;141:858900. https://doi.org/10.1037/a0038498.

9. De Zeeuw EL, van Beijsterveldt CEM, Hoestra RA, Bartels M, Boomsma DI. The etiology of autistic traits in preschoolers: a population-based twin study. J Child Psychiatry Psychol. 2017;58:893-901.

10. Hoekstra RA, Bartels M, Hudziak JJ, Van Beijsterveldt TCEM, Boomsma DI. Genetic and environmental influences on the stability of withdrawn behavior in children: a longitudinal, multi-informant twin study. Behav Genet. 2008:38:447-61. https://doi.org/10.1007/s10519-008-9213-4.

11. Ivanova MY, Achenbach TM, Dumenci L, Rescorla LA, Almqvist F, Weintraub S, et al. Testing the 8-syndrome structure of the $C B C L$ in 30 societies. J Clin Child Adolesc Psychol. 2007;36:405-17. https://doi. org/10.1080/15374410701444363.

12. Ivanova MY, Achenbach TM, Rescorla LA, Bilenberg N, Bjarnadottir G, Denner $\mathrm{S}$, et al. Syndromes of preschool psychopathology reported by teachers and caregivers in 14 societies using the Caregiver-Teacher Report Form (C-TRF). J Early Childhood Infant Psychol. 2011;7:87-103.

13. Ivanova MY, Achenbach $T M$, Rescorla LA, Dumenci $L$, Almqvist $F$, Bathiche $M$, et al. Testing the Teacher's Report Form syndromes in 20 societies. School Psychol Rev. 2007;36:468-83.

14. Ivanova MY, Achenbach TM, Rescorla LA, Dumenci L, Almqvist F, Bilenberg $N$, et al. The generalizability of the Youth Self-Report syndrome structure in 23 societies. J Consult Clin Psychol. 2007;75:729-38. https:// doi.org/10.1037/0022-006X.75.5.729.

15. Ivanova MY, Achenbach TM, Rescorla LA, Harder VS, Ang RP, Bilenberg $\mathrm{N}$, et al. Preschool psychopathology reported by parents in 23 societies. Testing the seven-syndrome model of the Child Behavior Checklist for Ages 1.5-5. J Am Acad Child Adolesc Psychiatry. 2010;49:1215-24. https ://doi.org/10.1016/j.jaac.2010.08.019.

16. Ivanova MY, Achenbach TM, Rescorla LA, Turner LV, Ahmeti-Pronaj A, Au A, et al. Syndromes of self-reported psychopathology for ages 18-59 in 29 societies. J Psychopathol Behav Assess. 2015;37:171-83. 
17. Ivanova MY, Achenbach TM, Rescorla LA, Turner LV, Árnadóttir HA, Au A, et al. Syndromes of collateral-reported psychopathology for ages 18-59 in 18 societies. Int J Clin Health Psychol. 2015;15:18-28.

18. Ivanova MY, Achenbach TM, Rescorla LA, Turner LV, Dumas JA, et al. Syndromes of collateral-reported psychopathology of later life in 12 societies. 2019a (submitted for publication)

19. Ivanova MY, Achenbach TM, Rescorla LA, Turner LV, Dumas JA, et al. The generalizability of empirically derived syndromes of self-reported elder psychopathology across 20 societies. 2019b (submitted for publication)

20. Ormel J, Oldehinkel AJ, Sijtsema JJ, et al. The TRacking Adolescents' Individual Lives Survey (TRAILS). Design, current status and selected findings. J Am Acad Child Adolesc Psychiatry. 2012;51:1020-36. https://doi. org/10.1016/j.jaac.2012.08.004.

21. Raine A, Portnoy J, Liu J, Mahoomed T, Hibbeln JR. Reduction in behavior problems with omega-3 supplementation in children aged 8-16 years: a randomized, double-blind, placebo-controlled, stratified, parallel-group trial. J Child Psychol Psychiatry. 2015;56:509-20.

22. Reef J, van Meurs I, Verhulst FC, van der Ende J. Children's problems predict adults' DSM-IV disorders across 24 years. J Am Acad Child AdolesC Psychiatry. 2010;49:1117-24.

23. Rescorla LA, Althoff RR, Ivanova MY, Achenbach TM. Effects of society and culture on parents' ratings of children's problems in 45 societies. Eur Child Adolesc Psychiatry. 2019. https://doi.org/10.1007/s00787-018-01268-3.

24. Rescorla LA, Ivanova MY, Achenbach TM, Begovac I, Chahed M, Drugli MB, et al. International epidemiology of child and adolescent psychopathology: 2. Integration and applications of dimensional findings from 44 societies. J Am Acad Child Adolesc Psychiatry. 2012;51:1273-83.

25. Tiemeier H, Velders FP, Szekely E, Roza SJ, Dieleman G, Jaddoe VWV, et al. The Generation R Study: a review of design, findings to date, and a study of the 5-HTTLPR by environmental interaction from fetal life onward. J Am Acad Child Adolesc Psychiatry. 2012;51(1119-1135):e7.

26. Van Meurs I, Reef J, Verhulst F, van der Ende J. Intergenerational transmission of child problem behaviors: a longitudinal, population-based study. J Am Acad Child Adolesc Psychiatry. 2009;48:138-45.

27. Vidair HB, Reyes JA, Shen S, Parrilla-Escobar MA, Heleniak CM, Hollin IL, Woodruff S, Turner JB, Rynn MA. Screening parents during child evaluations: exploring parent and child psychopathology in the same clinic. J Am Acad Child Adolesc Psychiatry. 2011;50:441-50.

28. Wadsworth ME, Achenbach TM. Explaining the link between low socioeconomic status and psychopathology: testing two mechanisms of the social causation hypothesis. J Consult Clin Psychol. 2005;73:1146-53. https://doi.org/10.1037/0022-006X.73.6.1146.

29. Wesseldiji LW, Dieleman GC, van Steensel FJA, Bartels M, Hudziak J, Lindauer RJL, Middeldorp CM. Risk factors for parental psychopathology: a study in families with children or adolescents with psychopathology. Eur Child Adolesc Psychiatry. 2018;27:1575-84.

\section{Publisher's Note}

Springer Nature remains neutral with regard to jurisdictional claims in published maps and institutional affiliations.
Ready to submit your research? Choose BMC and benefit from:

- fast, convenient online submission

- thorough peer review by experienced researchers in your field

- rapid publication on acceptance

- support for research data, including large and complex data types

- gold Open Access which fosters wider collaboration and increased citations

- maximum visibility for your research: over $100 \mathrm{M}$ website views per year

At BMC, research is always in progress.

Learn more biomedcentral.com/submissions 